\title{
Intestinal Fibrosis and Liver Fibrosis: Consequences of Chronic Inflammation or Independent Pathophysiology?
}

\author{
Florian Rieder ${ }^{a}$ b Dominik Bettenworth ${ }^{c}$ Jin Imai ${ }^{d, e}$ Yutaka Inagaki ${ }^{d, f}$ \\ ${ }^{a}$ Department of Gastroenterology and Hepatology, Digestive Disease Institute, and ${ }^{b}$ Department of \\ Pathobiology, Lerner Research Institute, Cleveland Clinic Foundation, Cleveland, Ohio, USA; ${ }^{C}$ Department of \\ Medicine B, University Hospital of Münster, Münster, Germany; ${ }^{d}$ Center for Matrix Biology and Medicine, \\ Graduate School of Medicine, Tokai University, and Departments of ${ }^{\mathrm{e}}$ Gastroenterology and ${ }^{\mathrm{f}}$ Regenerative \\ Medicine, Tokai University School of Medicine, Isehara, Japan
}

\section{Key Words}

Organ fibrosis · Inflammatory bowel disease - Liver cirrhosis .

Extracellular matrix

\begin{abstract}
Background: Intestinal fibrosis and liver fibrosis represent a significant burden for our patients and health-care systems. Despite the severe clinical problem and the observation that fibrosis is reversible, no specific antifibrotic therapies exist. Summary: In this review, using an 'East-West' scientific collaboration, we summarize the current knowledge on principal mechanisms shared by intestinal fibrosis and liver fibrosis. We furthermore discuss inflammation as the cause of fibrogenesis in both entities, depict unique features of intestinal and hepatic fibrosis, and provide a future outlook on the development of antifibrotic therapies. Key Messages: A collaborative effort in the field of fibrosis, covering multiple organ systems, will have the highest chance of leading to the development of a successful antifibrotic intervention.
\end{abstract}

(c) 2016 S. Karger AG, Basel

\section{Introduction}

Fibrosis is characterized by an exaggerated accumulation of extracellular matrix (ECM) proteins and an expansion of mesenchymal cells [1]. Fibrotic alterations can be recognized in several different organs of the human body such as the skin, lung, kidney, liver, and the gut. With regard to the latter, clinically apparent fibrosis is most frequently associated with Crohn's disease (CD), a chronic inflammatory intestinal disorder with unknown etiology $[2,3]$. More specifically, within the first 10 years after diagnosis, up to $50 \%$ of CD patients will develop a penetrating or stricturing course of disease $[2,4]$. Patients suffering from stricturing CD may present with a persistent luminal narrowing that can lead to obstructive symptoms and an impaired quality of life. While inflammatory strictures may respond to anti-inflammatory medical treatment, fibrostenotic strictures do not resolve upon immunosuppressive therapy. Due to the paucity of antifibrotic drugs for intestinal fibrosis [5], CD-associated

\section{KARGER}

E-Mail karger@karger.com www.karger.com/iid (c) 2016 S. Karger AG, Basel

2296-9403/16/0011-0041\$39.50/0 
Fig. 1. Distribution of vitamin A-storing stellate cells in the lamprey. In the lamprey, vitamin A-storing cells represent the visceral type of fibroblasts that are present uniformly in the organs of splanchnic and intermediate mesodermal origin. These are distinguishable from the cells of somatic mesodermal origin such as dermal fibroblasts. Especially, abundant vitamin Astoring cells are found in the lamina propria of the gastrointestinal mucosa in the lamprey. Reproduced with permission from Wold et al. [11].

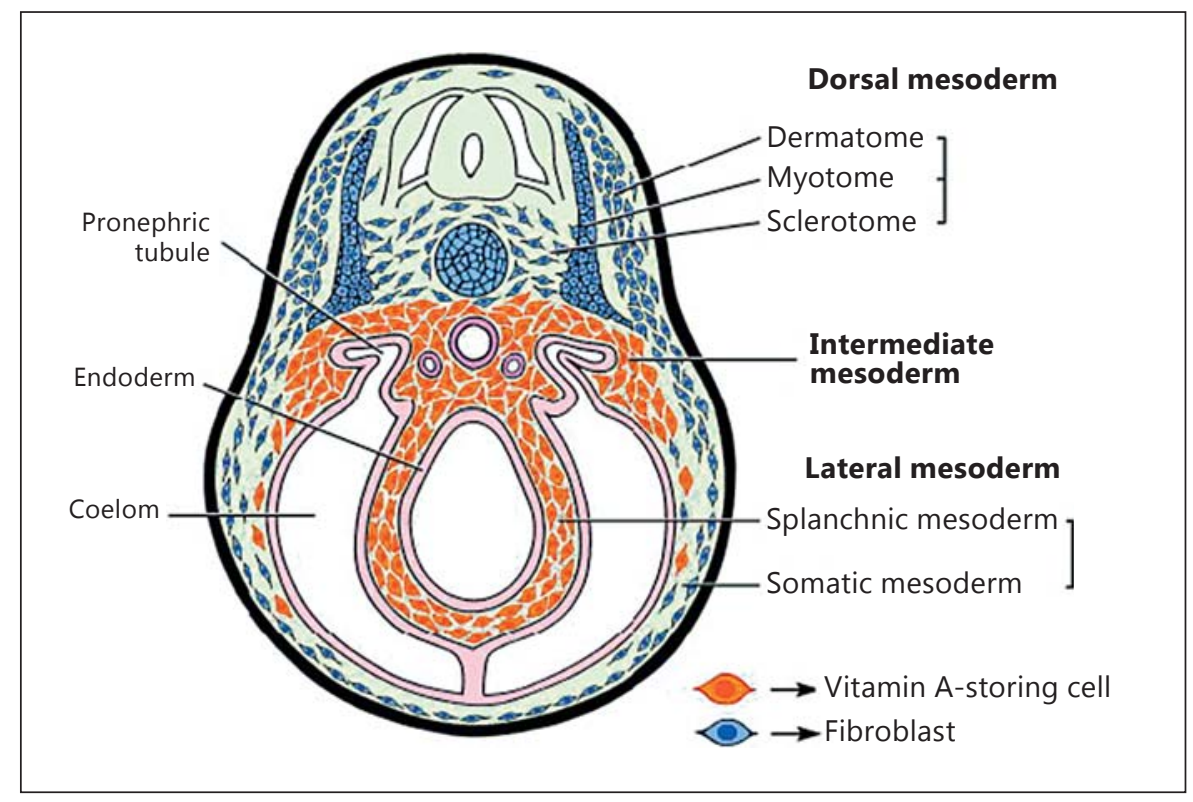

fibrotic strictures are a major reason why approximately $75 \%$ of CD patients have to undergo surgery at least once during their lifetime [6].

In the context of chronic liver diseases, hepatitis B and $\mathrm{C}$ viruses (HBV and $\mathrm{HCV}$ ) are among the most frequent causes for the development of liver fibrosis [7-9]. The progression from fibrosis to liver cirrhosis is of particular importance for affected patients, since the risk for hepatocellular carcinoma is significantly increased in the cirrhotic liver $[8,9]$. Comparable to intestinal fibrosis in CD, where several mechanisms were identified to drive fibrogenesis, including cytokines, chemokines, or mesenchymal cells, the same players have been found during the manifestation of liver fibrosis.

In this review, we summarize the current knowledge on principal mechanisms shared by intestinal fibrosis and liver fibrosis. We furthermore discuss inflammation as the cause of fibrogenesis in both entities and depict unique features of intestinal and hepatic fibrosis.

\section{Cellular Basis of Fibrosis}

The main effector cell mediating intestinal fibrosis is considered the intestinal mesenchymal cell that is responsible for the excessive synthesis of ECM proteins. It exists in three distinct forms: the fibroblast [vimentin positive, $\alpha$-smooth muscle actin ( $\alpha$-SMA) negative, desmin negative], the myofibroblast (vimentin positive, $\alpha$-SMA posi- tive, desmin negative), and the smooth muscle cell (vimentin positive, a-SMA positive, desmin positive). Mesenchymal cells can actively differentiate and de-differentiate between these cellular phenotypes.

The liver is unique in the sense that hepatic stellate cells (HSCs), fibroblast or myofibroblast precursor cells located within the space of Disse along the hepatic sinusoid, play the central role in hepatic fibrogenesis. HSCs have a characteristic feature in that they possess fat droplets containing vitamin A [10]. During the course of chronic liver injury and inflammation, HSCs activated by profibrotic mediators, such as platelet-derived growth factor or transforming growth factor- $\beta$ (TGF- $\beta$ ), transform into myofibroblasts and deposit ECM in the liver parenchyma, resulting in liver fibrosis.

Such vitamin A-containing stellate cells were originally considered liver specific. However, the same types of cells are now recognized in the pancreas, kidney, and lung, contributing to organ fibrosis. From the viewpoint of the common origin of collagen-producing cells in the liver and intestine, abundant vitamin A-storing cells have been found in the lamina propria of the gastrointestinal mucosa in the lamprey, an observation that could be relevant to humans [11]. These vitamin A-storing cells may differentiate into the visceral type of fibroblasts that are distinguishable from dermal fibroblasts of somatic mesodermal origin (fig. 1). On the other hand, a recent gene expression analysis of fibroblasts present in various organs has indicated that human fibroblasts present in the gastrointesti- 
nal tract have a significantly different gene expression profile from the profiles in other organs including the liver [12]. These findings suggest that the local environment could have a role in shaping fibroblast function.

A key feature of fibrosis of the liver and intestine aside activation of mesenchymal cells - is the expansion of the mesenchymal cell pool. This is highly relevant, since prevention of fibroblast accumulation could offer future therapeutic potential. A number of studies have reported that fibrocytes, which are circulating CD14+/ CD45+ collagen-producing cells derived from bone marrow, act as a precursor of myofibroblasts and contribute to the progression of clinical and experimental liver fibrosis $[13,14]$. However, subsequent studies using type I collagen reporter mice have shown that the direct contribution of fibrocytes and other blood-born collagen-producing cells to hepatic fibrogenesis is rather limited [15] or even negligible [16]. In the intestine, descriptive data are suggestive of a contribution of fibrocytes to fibrogenesis [17], but a functional evaluation is lacking.

Epithelial-mesenchymal transition (EMT) or endothelial-mesenchymal transition is a process in which fully mature epi- or endothelial cells acquire a spindle-shape morphology, loose their typical markers, and acquire a mesenchymal phenotype and function [18]. Contribution of EMT to the progression of liver fibrosis has been reported in parenchymal hepatocytes and biliary epithelial cells $[19,20]$. This finding, however, is controversial: a series of cell fate mapping experiments questioned EMT as an underlying mechanism of hepatic fibrogenesis [2123 ]. One report is available suggesting colonic EMT contributing to intestinal fibrogenesis [24], and inflammation-induced endothelial-mesenchymal transition has been shown to occur in vitro, in situ, and in vivo in intestinal inflammation [25], however, to a limited extent.

\section{Innate Immunity}

\section{Pathogen-Associated Molecular Patterns}

The majority of our microbes are found in the gut and influence health and disease. Alterations in the immune system, the microflora, or the barrier function of the intestine leading to bacterial translocation into the intestinal mucosa or portal circulation can change host-microbiome interaction and lead to inflammation. Essentially, all intestinal as well as hepatic immune and nonimmune cells sense microbe-derived pathogen-associated molecular patterns (PAMPs) through pattern recognition receptors [26].

Intestinal and Liver Fibrosis
Evidence about the influence of microbial composition or sensing on intestinal fibrosis can be derived from human genetic studies. Gene variants affecting innate immunity, located in or near genes involved in bacterial recognition and processing, such as NOD2 [27], are associated with fibrostenosing inflammatory bowel disease (IBD). Comparable genes have been linked to complicated IBD, and the risk of these complications increases proportionally with the number of variants carried by the patient [28]. Circulating antibodies against microbial peptides are qualitatively and quantitatively associated with and predictive of a more complicated disease phenotype [29]. In addition, essentially all animal models of intestinal fibrosis appear to be dependent on the presence of a microflora to initiate or perpetuate gut inflammation and fibrosis [25]. Although direct evidence about the innate immunity gene variants in liver fibrosis is lacking, several studies have shown that NOD2 is associated with the increased mortality in nonalcoholic liver transplant patients [30] or the increased risk of spontaneous bacterial peritonitis in patients with liver cirrhosis $[31,32]$.

On a molecular level, fibroblasts and stellate cells in the intestine and liver express multiple pattern recognition receptors such as Toll-like receptors (TLRs) and Nod-like receptors [33-36] that can activate them towards a profibrogenic phenotype. Most information about innate immune signaling and fibrosis is available in the liver. Translocation of bacteria or their products to the liver, lipopolysaccharide in the portal vein, or activation of TLR4 promote liver fibrogenesis $[34,37,38]$. Lipopolysaccharide also downregulates the TGF- $\beta 1$ decoy receptor $\mathrm{BAMBI}$ and hence indirectly contributes to fibrogenesis increasing HSC susceptibility to TGF- $\beta 1$ [34]. A different PAMP, the TLR5 ligand flagellin (present in all flagellated bacteria), induces a proinflammatory and profibrotic phenotype in primary human intestinal fibroblasts [36], as well as promotes fibroblast proliferation [39]. Colonic EMT occurs after ligation of the TLR4 variant D299G [40]. This not only suggests a different location of action of PAMPs on fibrogenesis in the liver and intestine but also indicates that different microbial peptides may be active in the liver and intestine.

\section{Monocytes/Macrophages}

Hepatic macrophages play divergent roles in both the progression and regression of liver fibrosis, depending on the stage of fibrosis development [41]. Macrophage plasticity and polarization appear to be critical in this process. In early liver fibrosis, macrophages can act in a profibrogenic fashion through the production of profibrotic me- 
Fig. 2. TGF- $\beta /$ Smad signal and its antagonists in organ fibrosis. TGF- $\beta$ and its intracellular mediators, the Smad proteins, are the most potent accelerators of collagen production in the liver and intestine. TGF- $\beta$ not only promotes collagen production but also activates HSCs and myofibroblasts and suppresses MMP expression, leading to the progression of liver and intestinal fibrosis. Among the Smad/BMP superfamily members, Smad 3 plays a pivotal role in stimulating collagen gene transcription, while Smad 7 inhibits the TGF- $\beta$ signal by suppressing the phosphorylation and the subsequent nuclear translocation of Smad 3. BMP7 and hepatocyte growth factor (HGF) have been reported to suppress organ fibrosis by counteracting TGF- $\beta$ action on the type I collagen gene.

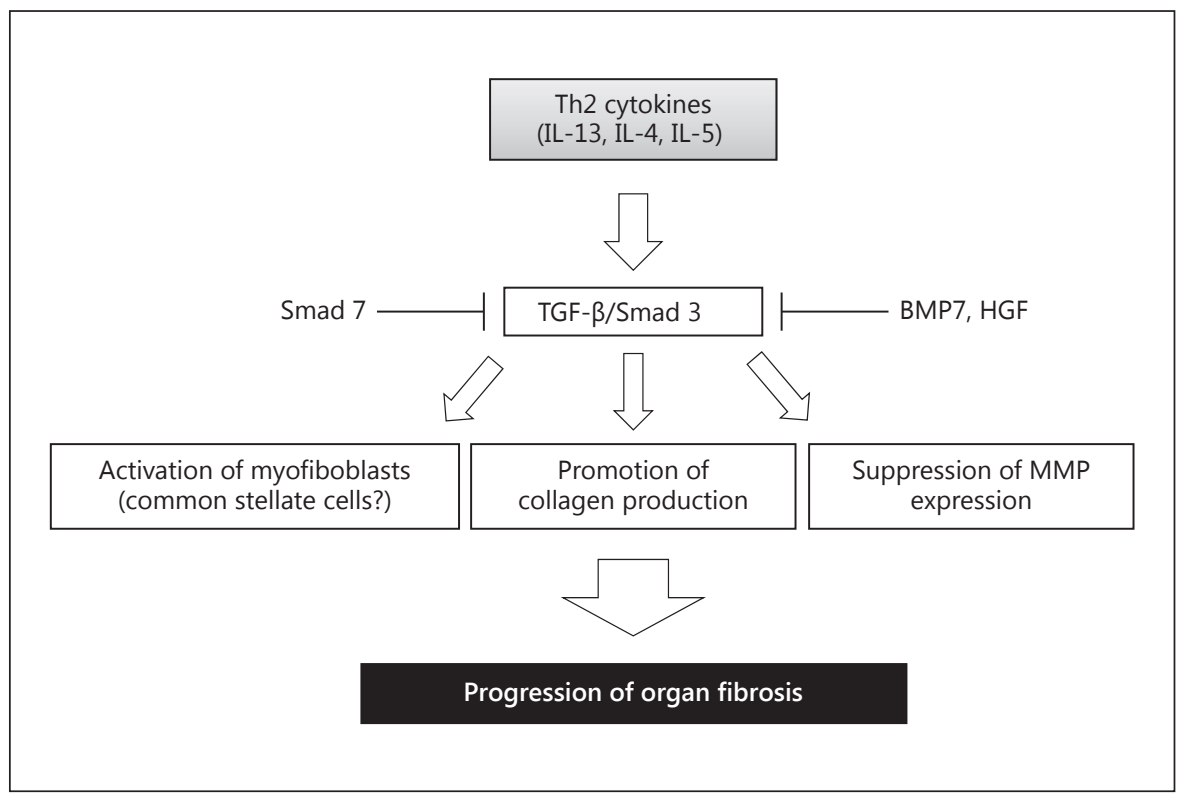

diators, such as TGF- $\beta$, leading to HSC activation. In contrast, macrophages have been implicated in liver fibrosis resolution as well, possibly through the production of matrix metalloproteinases (MMPs), induction of apoptosis in HSCs, elimination of apoptotic cells, or secretion of IL-10 [41-47]. Hepatic recruitment of macrophages also plays a pivotal role in the fibrosis progression of experimental steatohepatitis [48, 49].

In contrast to the abundant data from the liver, information is lacking on an effect of macrophages and macrophage subsets on the initiation or resolution of intestinal fibrosis.

\section{Cytokines}

TGF- $\beta$ and its intracellular mediators, Smad proteins, are the most potent signal to promote collagen production in the liver and intestine. Several factors increasing the expression of TGF- $\beta$ or its activation, including MMPs, plasmin, plasminogen activators, av $\beta 6$ integrin, and thrombospondins, have been reported [50].

TGF- $\beta$ exerts a wide variety of functions in liver and intestinal fibrosis. It not only promotes collagen production, but also activates HSCs and myofibroblasts and suppresses MMP expression (fig. 2). During the past two decades, a large number of studies have been focusing on the molecular mechanisms responsible for the TGF- $\beta$ stimulated type I collagen gene transcription and its pathological roles during the fibrotic process [50, 51]. Our group has succeeded in suppressing liver fibrosis by promoting the nuclear translocation of YB-1 that is a downstream effector of interferon- $\gamma[52]$. Among many factors that interact with the TGF- $\beta /$ Smad signal, bone morphogenetic protein (BMP) 7 [53] and hepatocyte growth factor [54] have been shown to suppress liver fibrosis by counteracting TGF- $\beta$ action on the type I collagen gene.

TGF- $\beta$ also drives intestinal stricture formation in IBD [55]. Levels of TGF- $\beta 1$ are increased in the intestinal mucosa of ulcerative colitis and CD patients [56]. TGF- $\beta 1$ is also elevated in models of chronic experimental colitis and accompanies increased collagen production [57]. In agreement with these observations, our recent study has shown that a small compound interfering with the TGF- $\beta$ signal suppresses experimental intestinal fibrosis [58] as it did for murine liver fibrosis [52]. Surprisingly, TGF- $\beta 1$ has not been shown to have a definitive role in promoting the numerical expansion of intestinal fibroblasts in vitro, despite doing so in other tissues and organs [59]. In a mouse model of colonic TGF- $\beta 1$ overexpression achieved via adenoviral transfer, animals developed a rapid accumulation of fibroblasts and thickening of the bowel wall [60]. These effects could be a direct effect of TGF- $\beta 1$ itself or, alternatively, be an indirect effect of this growth factor by inducing the synthesis of connective tissue growth factor, platelet-derived growth factor, and insulin-like growth factor I. The presence of an indirect 
effect is supported by gene expression studies that have revealed an upregulation of TGF- $\beta 1$ and connective tissue growth factor transcript levels in strictured CD tissue [61].

While the scientific rationale for TGF- $\beta 1$ in fibrosis is strong, it needs to be considered that it is not only crucially involved in fibrogenesis but also functions as a key regulator of cellular differentiation, proliferation, transformation, tumor suppression, as well as immunoregulation, and its actions may be context dependent. TGF- $\beta 1$ deficient mice develop severe multiorgan inflammation $[62,63]$, and targeted deletion of Smad 2 and Smad 4 is associated with early death in mice $[64,65]$, indicating the need for caution in using anti-TGF strategies as an antifibrotic therapy. Interestingly, a recent clinical study has reported that a Smad 7 antisense oligonucleotide (enhancing the TGF- $\beta$ signal) is effective as anti-inflammatory treatment of human $\mathrm{CD}$ without promoting stricture formation in the short term [66].

A change in the CD4+ T-cell profile towards Th2 predominance, as indicated through elevations in IL-4, IL-5, and IL-13, has been reported during the course of fibrosis in various organs [67]. IL-13 mediates, through binding to its IL-13R $\alpha$, an increased production of TGF- $\beta$ [68]. In the liver, Th2-associated alternative Kupffer cell activation promotes liver fibrosis [69]. Blockade of IL-13 significantly suppressed experimental liver fibrosis by repressing TGF- $\beta$ production [70].

In the intestine, an increased amount of IL-13 transcripts was detected in fibrotic intestinal samples from $\mathrm{CD}$ patients compared to noninflamed areas of the same patients [71]. Inhibition of IL-13 signaling by the administration of a small interfering RNA targeting the IL13- $\alpha 2$ receptor attenuated inflammation-associated murine intestinal fibrosis [72]. To the contrary, a study showed no difference in IL-13 production in the mucosal explants and lamina propria mononuclear cells between patients with stricturing $\mathrm{CD}$ and control subjects [73].

In experimental studies, IL-17A was involved in the pathogenesis of liver fibrosis by activating both Kupffer cells and HSCs [74, 75]. Likewise, IL-17 expression levels were elevated in experimental intestinal fibrotic tissues $[72,76]$. In CD patients, IL-17A but not IL-17E was overexpressed in tissue samples from intestinal strictures as compared to samples from nonstrictured areas in the same patients and compared to healthy colonic samples from control subjects [77]. While targeting of IL-12/IL-23 by anti-IL-23 p19 monoclonal antibody [78] ameliorated acute and chronic murine colitis, administration of the human anti-IL-17A antibody secukinumab failed to in- duce remission in $\mathrm{CD}$ patients [79]. Further studies are necessary prior to any clinical application of an anti-IL17-based strategy for the treatment of intestinal fibrosis.

\section{Matrix Turnover}

The imbalance between the production and degradation of ECM is observed commonly in various fibrotic diseases and represents a promising target for antifibrotic approaches [5]. Degradation of the ECM components is regulated by the enzymatic activity of MMPs [80], which is affected by the expression of tissue inhibitors of metalloproteinase (TIMPs). One mechanism, by which TGF- $\beta 1$ leads to fibrosis, is the creation of an imbalance of TIMP-1/MMP expression in favor of TIMP-1 [81]. TIMP-1 also exerts an antiapoptotic effect on HSCs [82]. Transgenic overexpression of TIMP-1 in the murine liver attenuates the spontaneous recovery from carbon tetrachloride-induced liver fibrosis by decreasing the active form of MMP-2 [83]. Along the same line, the use of MMP-9 mutant proteins as TIMP-1 scavengers reduced fibrosis by enhancing matrix resorption [84].

In intestinal strictures, TIMP-1 expression is increased in the mucosa overlying fibrotic areas compared to those in the nonfibrotic area, while MMP-3 and MMP-12 are downregulated in $\mathrm{CD}$ [55]. On the other hand, it has been reported that colonic tissue expression of MMP-1, MMP2, MMP-3, and MMP-9 is significantly increased in samples from the inflamed mucosa as compared to noninflamed mucosal samples in IBD [85]. Serum MMP-9 levels are increased and correlate with disease activity in pediatric CD patients [86]. Since MMP-2 and MMP-9 also possess proinflammatory potential, their use as antifibrotic reagents in liver and intestinal fibrosis may be hampered.

\section{Future Perspectives}

The ultimate treatment goal for fibrotic complications would be to stop or even reverse the fibrotic process. Great attention has been devoted to the phenomenon of reversibility of fibrosis in the field of hepatology [87]. Liver fibrosis, especially cirrhosis, was originally considered progressive and irreversible. However, a number of clinical studies have shown that it can be reversed if the causative agents are adequately removed or the patients are effectively treated [88-90]. With the advent of novel antiviral compounds that effectively inhibit HBV prolifera- 
tion [91], or even completely eradicate HCV [92], the impact of 'trigger elimination' on the reversibility of fibrosis/cirrhosis can be easily studied in human patients. Indeed, there are several studies demonstrating that effective virus suppression in $\mathrm{HBV}$-positive patients resulted in cirrhosis regression as proved by repetitive liver biopsies. Interestingly, this effect was independent from the antiviral agent used [93-95]. The same holds true for HCV infection, where studies report cirrhosis reversibility rates of up to $70-90 \%$ upon treatment with modern direct-acting agents $[90,96]$. Consistent with such clinical evidence for the reversibility of liver fibrosis, we have previously reported that bone marrow-derived cells migrating into fibrotic liver contribute to the regression of experimental liver fibrosis by expressing MMP-13 and MMP-9 [97]. The concept of reversibility of intestinal fibrosis is in concordance with various observations from other organs such as the skin, kidney, lung, or heart [98103].

In contrast to virus-induced liver fibrosis, $\mathrm{CD}$-associated fibrostenotic strictures are likely a result of ongoing intestinal inflammation, which cannot be attributed to a single pathogenic factor. When fibrostenotic strictures are already present, they are considered permanent and nonreversible. This notion, however, has to be challenged. Recently, a large combined analysis assessing the efficacy of strictureplasty in $\mathrm{CD}$ found an overall symptomatic recurrence rate of 39\% for jejunoileal strictures and 36\% for ileocolonic strictures. Strikingly, only 3 or $20 \%$, respectively, of CD patients' strictures were found at the previous site of strictureplasty [104]. This finding indicates that surgical intervention has the potential to stop progressing or even to reverse intestinal fibrosis [105]. Serial ultrasound examinations in patients after stricture- plasty found a reduced thickness of the intestinal wall [106] also suggesting that intestinal fibrosis is not only a one-way street.

As long as no single pathogenic factor for $\mathrm{CD}$ has been identified, potential antifibrotic treatment approaches for stricturing CD should focus on receptor-ligand interactions, pathways of fibrosis regression (e.g. TGF- $\beta$ ), or stimulate the resolution of fibrosis (e.g. TIMP antagonists). As discussed above, multiple distinct signaling cascades and mechanisms have been identified to contribute to fibrosis in the intestine and liver. Therefore, future therapeutic approaches should not only address a single but multiple targets in the form of a combined approach. The complexity of their interactions is high. It is obvious that quality, quantity, and timing of profibrotic mediators deserve thoughtful attention. Targeting individual cell types over mediators could be a promising approach. Activating subpopulations of macrophages to increase MMP expression and the induction of myofibroblast apoptosis may be suitable and may serve as an antifibrotic therapeutic armamentarium [107]. Another approach could be the stimulation of MMP production, which has been successfully performed in animal studies [5, 108, 109].

We have summarized the current knowledge on mechanisms of fibrosis which are shared by intestinal and liver fibrosis as well as their unique features. A collaborative effort in the field of fibrosis, covering multiple organ systems, will have the highest chance of leading to the development of a successful antifibrotic intervention.

\section{Disclosure Statement}

F.R. is on the advisory board of AbbVie. The other authors have no conflicts of interest to declare.

\section{References}

1 Friedman SL, Sheppard D, Duffield JS, et al: Therapy for fibrotic diseases: nearing the starting line. Sci Transl Med 2013;5:167sr1.

-2 Solberg IC, Vatn MH, Hoie O, et al: Clinical course in Crohn's disease: results of a Norwegian population-based ten-year follow-up study. Clin Gastroenterol Hepatol 2007;5: 1430-1438.

3 Baumgart DC, Sandborn WJ: Crohn's disease. Lancet 2012;380:1590-1605.

4 Cosnes J, Gower-Rousseau C, Seksik P, et al: Epidemiology and natural history of inflammatory bowel diseases. Gastroenterology 2011;140:1785-1794.
5 Bettenworth D, Rieder F: Medical therapy of stricturing Crohn's disease: what the gut can learn from other organs - a systematic review. Fibrogenesis Tissue Repair 2014;7:5.

6 Cosnes J, Nion-Larmurier I, Beaugerie L, et al: Impact of the increasing use of immunosuppressants in Crohn's disease on the need for intestinal surgery. Gut 2005;54:237-241.

7 Lauer GM, Walker BD: Hepatitis C virus infection. N Engl J Med 2001;345:41-52.

$>8$ Trepo C, Chan HL, Lok A: Hepatitis B virus infection. Lancet 2014;384:2053-2063.

$\checkmark$ Webster DP, Klenerman P, Dusheiko GM: Hepatitis C. Lancet 2015;385:1124-1135.
10 Ito T, Nemoto M: Kupffer's cells and fat storing cells in the capillary wall of human liver (in Japanese). Okajimas Folia Anat Jpn 1952; 24:243-258.

11 Wold HL, Wake K, Higashi N, et al: Vitamin A distribution and content in tissues of the lamprey, Lampetra japonica. Anat Rec A Discov Mol Cell Evol Biol 2004;276:134-142.

12 Higuchi Y, Kojima M, Ishii G, et al: Gastrointestinal fibroblasts have specialized, diverse transcriptional phenotypes: a comprehensive gene expression analysis of human fibroblasts. PLoS One 2015;10:e0129241. 
13 Baba S, Fujii H, Hirose T, et al: Commitment 28 Weersma RK, Stokkers PC, Cleynen I, et al: of bone marrow cells to hepatic stellate cells in mouse. J Hepatol 2004;40:255-260.

14 Forbes SJ, Russo FP, Rey V, et al: A significant proportion of myofibroblasts are of bone marrow origin in human liver fibrosis. Gastroenterology 2004;126:955-963.

15 Kisseleva T, Uchinami H, Feirt N, et al: Bone marrow-derived fibrocytes participate in pathogenesis of liver fibrosis. J Hepatol 2006; 45:429-438.

16 Higashiyama R, Moro T, Nakao S, et al: Negligible contribution of bone marrow-derived cells to collagen production during hepatic fibrogenesis in mice. Gastroenterology 2009; 137:1459-1466.e1

17 Uehara H, Nakagawa T, Katsuno T, et al: Emergence of fibrocytes showing morphological changes in the inflamed colonic mucosa. Dig Dis Sci 2010;55:253-260.

18 Kalluri R, Neilson EG: Epithelial-mesenchymal transition and its implications for fibrosis. J Clin Invest 2003;112:1776-1784.

19 Zeisberg M, Yang C, Martino M, et al: Fibroblasts derive from hepatocytes in liver fibrosis via epithelial to mesenchymal transition. J Biol Chem 2007;282:23337-23347.

20 Robertson H, Kirby JA, Yip WW, et al: Biliary epithelial-mesenchymal transition in posttransplantation recurrence of primary biliary cirrhosis. Hepatology 2007;45:977981.

21 Taura K, Miura K, Iwaisako K, et al: Hepatocytes do not undergo epithelial-mesenchymal transition in liver fibrosis in mice. Hepatology 2010;51:1027-1036.

-22 Scholten D, Osterreicher CH, Scholten A, et al: Genetic labeling does not detect epithelial-to-mesenchymal transition of cholangiocytes in liver fibrosis in mice. Gastroenterology 2010;139:987-998.

23 Chu AS, Diaz R, Hui JJ, et al: Lineage tracing demonstrates no evidence of cholangiocyte epithelial-to-mesenchymal transition in $\mathrm{mu}$ rine models of hepatic fibrosis. Hepatology 2011;53:1685-1695.

24 Flier SN, Tanjore H, Kokkotou EG, et al: Identification of epithelial to mesenchymal transition as a novel source of fibroblasts in intestinal fibrosis. J Biol Chem 2010;285: 20202-20212.

25 Rieder F, Kessler S, Sans M, et al: Animal models of intestinal fibrosis: new tools for the understanding of pathogenesis and therapy of human disease. Am J Physiol Gastrointest Liver Physiol 2012;303:G786-G801.

-26 Takeuchi O, Akira S: Pattern recognition receptors and inflammation. Cell 2010;140: 805-820.

27 Adler J, Rangwalla SC, Dwamena BA, et al: The prognostic power of the NOD2 genotype for complicated Crohn's disease: a meta-analysis. Am J Gastroenterol 2011;106: 699-712. Confirmation of multiple Crohn's disease susceptibility loci in a large Dutch-Belgian cohort. Am J Gastroenterol 2009;104:630638 .

29 Rieder F, Lawrance IC, Leite A, et al: Predictors of fibrostenotic Crohn's disease. In flamm Bowel Dis 2011;17:2000-2007.

30 Saner FH, Nowak K, Hoyer D, et al: A noninterventional study of the genetic polymorphisms of NOD2 associated with increased mortality in non-alcoholic liver transplant patients. BMC Gastroenterol 2014;14:4.

1 Appenrodt B, Grunhage F, Gentemann MG, et al: Nucleotide-binding oligomerization domain containing 2 (NOD2) variants are genetic risk factors for death and spontaneous bacterial peritonitis in liver cirrhosis. Hepatology 2010;51:1327-1333.

- 32 Bruns T, Peter J, Reuken PA, et al: NOD2 gene variants are a risk factor for culturepositive spontaneous bacterial peritonitis and monomicrobial bacterascites in cirrhosis. Liver Int 2012;32:223-230.

33 Uehara A, Takada H: Functional TLRs and NODs in human gingival fibroblasts. J Dent Res 2007;86:249-254.

34 Seki E, De Minicis S, Osterreicher $\mathrm{CH}$, et al: TLR4 enhances TGF- $\beta$ signaling and hepatic fibrosis. Nat Med 2007;13:1324-1332.

35 Otte JM, Rosenberg IM, Podolsky DK: Intestinal myofibroblasts in innate immune responses of the intestine. Gastroenterology 2003;124:1866-1878.

36 Rieder F, Bhilocha S, Schirbel A, et al: Activation of Toll-like receptor (TLR) 5 induces a pro-fibrogenic phenotype on human intestinal myofibroblasts (HIF) - a novel pathway mediated by caspase 1 (Abstract). Gastroenterology 2011;142:S116.

-37 Lin RS, Lee FY, Lee SD, et al: Endotoxemia in patients with chronic liver diseases: relationship to severity of liver diseases, presence of esophageal varices, and hyperdynamic circulation. J Hepatol 1995;22:165-172.

- 38 Chan CC, Hwang SJ, Lee FY, et al: Prognostic value of plasma endotoxin levels in patients 32:942-946.

39 Hasan UA, Trinchieri G, Vlach J: Toll-like receptor signaling stimulates cell cycle entry and progression in fibroblasts. J Biol Chem 2005;280:20620-20627.

40 Eyking A, Ey B, Runzi M, et al: Toll-like receptor 4 variant D299G induces features of neoplastic progression in Caco-2 intestinal cells and is associated with advanced human colon cancer. Gastroenterology 2012;141: 2154-2165.

41 Duffield JS, Forbes SJ, Constandinou CM, et al: Selective depletion of macrophages reveals distinct, opposing roles during liver injury and repair. J Clin Invest 2005;115:5665.

42 Henderson NC, Iredale JP: Liver fibrosis: cellular mechanisms of progression and resolution. Clin Sci (Lond) 2007;112:265-280. with cirrhosis. Scand J Gastroenterol 1997;
43 Popov Y, Sverdlov DY, Bhaskar KR, et al: Macrophage-mediated phagocytosis of apoptotic cholangiocytes contributes to reversal of experimental biliary fibrosis. Am J Physiol Gastrointest Liver Physiol 2010; 298:G323-G334.

44 Douglass A, Wallace K, Parr R, et al: Antibody-targeted myofibroblast apoptosis reduces fibrosis during sustained liver injury. J Hepatol 2008;49:88-98.

45 Zhou X, Murphy FR, Gehdu N, et al: Engagement of $\alpha v \beta 3$ integrin regulates proliferation and apoptosis of hepatic stellate cells. J Biol Chem 2004;279:23996-24006.

46 Friedman SL: Mac the knife? Macrophages - the double-edged sword of hepatic fibrosis. J Clin Invest 2005;115:29-32.

-47 Fallowfield JA, Mizuno M, Kendall TJ, et al: Scar-associated macrophages are a major source of hepatic matrix metalloproteinase-13 and facilitate the resolution of murine hepatic fibrosis. J Immunol 2007; 178:52885295.

48 Karlmark KR, Weiskirchen R, Zimmermann $\mathrm{HW}$, et al: Hepatic recruitment of the inflammatory Gr1+ monocyte subset upon liver injury promotes hepatic fibrosis. Hepatology 2009;50:261-274.

49 Seki E, De Minicis S, Gwak GY, et al: CCR1 and CCR5 promote hepatic fibrosis in mice. J Clin Invest 2009;119:1858-1870.

50 Inagaki Y, Okazaki I: Emerging insights into transforming growth factor $\beta$ Smad signal in hepatic fibrogenesis. Gut 2007;56:284-292.

51 Li C, Iness A, Yoon J, et al: Noncanonical STAT3 activation regulates excess TGF- $\beta 1$ and collagen I expression in muscle of stricturing Crohn's disease. J Immunol 2015;194: 3422-3431.

52 Higashi K, Tomigahara Y, Shiraki H, et al: A novel small compound that promotes nuclear translocation of YB-1 ameliorates experimental hepatic fibrosis in mice. J Biol Chem 2011;286:4485-4492.

53 Kinoshita K, Iimuro Y, Otogawa K, et al: Adenovirus-mediated expression of BMP-7 suppresses the development of liver fibrosis in rats. Gut 2007;56:706-714.

54 Inagaki $\mathrm{Y}$, Higashi K, Kushida M, et al: Hepatocyte growth factor suppresses profibrogenic signal transduction via nuclear export of Smad3 with galectin-7. Gastroenterology 2008; 134:1180-1190.

55 Di Sabatino A, Jackson CL, Pickard KM, et al: Transforming growth factor $\beta$ signalling and matrix metalloproteinases in the mucosa overlying Crohn's disease strictures. Gut 2009;58:777-789.

56 Babyatsky MW, Rossiter G, Podolsky DK Expression of transforming growth factors $\alpha$ and $\beta$ in colonic mucosa in inflammatory bowel disease. Gastroenterology 1996;110: 975-984. 
57 Fichtner-Feigl S, Fuss IJ, Young CA, et al: Induction of IL- 13 triggers TGF- $\beta 1$-dependent tissue fibrosis in chronic 2,4,6-trinitrobenzene sulfonic acid colitis. J Immunol 2007; 178:5859-5870.

58 Imai J, Hozumi K, Sumiyoshi H, et al: Antifibrotic effects of a novel small compound on the regulation of cytokine production in a mouse model of colorectal fibrosis. Biochem Biophys Res Commun 2015;468:554-560.

59 Lawrance IC, Maxwell L, Doe W: Altered response of intestinal mucosal fibroblasts to profibrogenic cytokines in inflammatory bowel disease. Inflamm Bowel Dis 2001;7: 226-236.

-60 Vallance BA, Gunawan MI, Hewlett B, et al: TGF- $\beta 1$ gene transfer to the mouse colon leads to intestinal fibrosis. Am J Physiol Gastrointest Liver Physiol 2005;289:G116G128.

-61 Burke JP, Ferrante M, Dejaegher K, et al: Transcriptomic analysis of intestinal fibrosis-associated gene expression in response to medical therapy in Crohn's disease. Inflamm Bowel Dis 2008;14:1197-1204.

62 Diebold RJ, Eis MJ, Yin M, et al: Early-onset multifocal inflammation in the transforming growth factor $\beta 1$-null mouse is lymphocyte mediated. Proc Natl Acad Sci USA 1995;92: 12215-12219.

-63 Kulkarni AB, Ward JM, Yaswen L, et al: Transforming growth factor- $\beta 1$ null mice. An animal model for inflammatory disorders. Am J Pathol 1995;146:264-275.

-64 Nomura M, Li E: Smad2 role in mesoderm formation, left-right patterning and craniofacial development. Nature 1998;393:786790.

65 Yang X, Li C, Xu X, et al: The tumor suppressor SMAD4/DPC4 is essential for epiblast proliferation and mesoderm induction in mice. Proc Natl Acad Sci USA 1998;95:36673672.

66 Monteleone G, Neurath MF, Ardizzone S, et al: Mongersen, an oral SMAD7 antisense oligonucleotide, and Crohn's disease. N Engl J Med 2015;372:1104-1113.

67 Morishima Y, Ishii Y: Targeting Th2 cytokines in fibrotic diseases. Curr Opin Investig Drugs 2010;11:1229-1238.

-68 Fichtner-Feigl S, Strober W, Kawakami K, et al: IL-13 signaling through the IL-13a2 receptor is involved in induction of TGF- $\beta 1$ production and fibrosis. Nat Med 2006; 12 : 99-106.

-69 Lopez-Navarrete G, Ramos-Martinez E, Suarez-Alvarez K, et al: Th2-associated alternative Kupffer cell activation promotes liver fibrosis without inducing local inflammation. Int J Biol Sci 2011;7:1273-1286.

70 Chiaramonte MG, Donaldson DD, Cheever AW, et al: An IL-13 inhibitor blocks the development of hepatic fibrosis during a $\mathrm{T}$ helper type 2-dominated inflammatory response. J Clin Invest 1999;104:777-785.
1 Bailey JR, Bland PW, Tarlton JF, et al: IL-13 promotes collagen accumulation in Crohn's disease fibrosis by down-regulation of fibroblast MMP synthesis: a role for innate lymphoid cells? PLoS One 2012; 7:e52332.

72 Fichtner-Feigl S, Strober W, Geissler EK, et al: Cytokines mediating the induction of chronic colitis and colitis-associated fibrosis. Mucosal Immunol 2008; 1(suppl 1):S24-S27.

73 Biancheri P, Di Sabatino A, Ammoscato F, et al: Absence of a role for interleukin-13 in inflammatory bowel disease. Eur J Immunol 2014;44:370-385.

74 Meng F, Wang K, Aoyama T, et al: Interleukin-17 signaling in inflammatory, Kupffer cells, and hepatic stellate cells exacerbates liver fibrosis in mice. Gastroenterology 2012; 143:765-776.e1-e3.

75 Hara M, Kono H, Furuya S, et al: Interleukin17A plays a pivotal role in cholestatic liver fibrosis in mice. J Surg Res 2013;183:574582.

76 Fichtner-Feigl S, Young CA, Kitani A, et al: IL-13 signaling via IL-13Ra2 induces major downstream fibrogenic factors mediating fibrosis in chronic TNBS colitis. Gastroenterology 2008;135:2003-2013.e1-e7.

77 Biancheri P, Pender SL, Ammoscato F, et al: The role of interleukin 17 in Crohn's diseaseassociated intestinal fibrosis. Fibrogenesis Tissue Repair 2013;6:13.

78 Yao JY, Lu Y, Zhi M, et al: Inhibition of the interleukin-23/interleukin-17 pathway by anti-interleukin-23p19 monoclonal antibody attenuates 2,4,6-trinitrobenzene sulfonic acid-induced Crohn's disease in rats. Mol Med Rep 2014;10:2105-2110.

79 Hueber W, Sands BE, Lewitzky S, et al: Secukinumab, a human anti-IL-17A monoclonal antibody, for moderate to severe Crohn's disease: unexpected results of a randomised, double-blind placebo-controlled trial. Gut 2012;61:1693-1700.

80 Rieder F, Fiocchi C: Intestinal fibrosis in IBD - a dynamic, multifactorial process. Nat Rev Gastroenterol Hepatol 2009;6:228-235.

$81 \mathrm{Ma}$ C, Chegini N: Regulation of matrix metalloproteinases (MMPs) and their tissue inhibitors in human myometrial smooth muscle cells by TGF- $\beta 1$. Mol Hum Reprod 1999; 5:950-954

82 Murphy FR, Issa R, Zhou X, et al: Inhibition of apoptosis of activated hepatic stellate cells by tissue inhibitor of metalloproteinase- 1 is mediated via effects on matrix metalloproteinase inhibition: implications for reversibility of liver fibrosis. J Biol Chem 2002;277: 11069-11076.

83 Yoshiji H, Kuriyama S, Yoshii J, et al: Tissue inhibitor of metalloproteinases-1 attenuates spontaneous liver fibrosis resolution in the transgenic mouse. Hepatology 2002;36:850860.

84 Roderfeld M, Weiskirchen R, Wagner S, et al: Inhibition of hepatic fibrogenesis by matrix metalloproteinase- 9 mutants in mice. FASEB J 2006;20:444-454.
85 Meijer MJ, Mieremet-Ooms MA, van der Zon AM, et al: Increased mucosal matrix metalloproteinase-1, -2, -3 and -9 activity in patients with inflammatory bowel disease and the relation with Crohn's disease phenotype. Dig Liver Dis 2007;39:733-739.

86 Kofla-Dlubacz A, Matusiewicz M, KrzystekKorpacka M, et al: Correlation of MMP-3 and MMP-9 with Crohn's disease activity in children. Dig Dis Sci 2012;57:706-712.

87 Friedman SL, Bansal MB: Reversal of hepatic fibrosis - fact or fantasy? Hepatology 2006; 43:S82-S88.

88 Shiratori Y, Imazeki F, Moriyama M, et al: Histologic improvement of fibrosis in patients with hepatitis $C$ who have sustained response to interferon therapy. Ann Intern Med 2000;132:517-524.

-89 Poynard T, McHutchison J, Manns M, et al: Impact of pegylated interferon $a-2 b$ and ribavirin on liver fibrosis in patients with chronic hepatitis C. Gastroenterology 2002; 122:1303-1313.

90 Marcellin P, Gane E, Buti M, et al: Regression of cirrhosis during treatment with tenofovir disoproxil fumarate for chronic hepatitis B: a 5-year open-label follow-up study. Lancet 2013;381:468-475.

91 Lok AS, McMahon BJ, Brown RS Jr, et al: Antiviral therapy for chronic hepatitis B viral infection in adults: a systematic review and meta-analysis. Hepatology 2016;63:284306.

92 Afdhal N, Reddy KR, Nelson DR, et al: Ledipasvir and sofosbuvir for previously treated HCV genotype 1 infection. N Engl J Med 2014;370:1483-1493.

$\$ 93$ Dienstag JL, Goldin RD, Heathcote EJ, et al: Histological outcome during long-term lamivudine therapy. Gastroenterology 2003; 124:105-117.

94 Hadziyannis SJ, Tassopoulos NC, Heathcote EJ, et al: Long-term therapy with adefovir dipivoxil for HBeAg-negative chronic hepatitis B for up to 5 years. Gastroenterology 2006;131:1743-1751.

95 Schiff ER, Lee SS, Chao YC, et al: Long-term treatment with entecavir induces reversal of advanced fibrosis or cirrhosis in patients with chronic hepatitis B. Clin Gastroenterol Hepatol 2011;9:274-276.

96 Lee YA, Wallace MC, Friedman SL: Pathobiology of liver fibrosis: a translational success story. Gut 2015;64:830-841.

97 Higashiyama R, Inagaki Y, Hong YY, et al: Bone marrow-derived cells express matrix metalloproteinases and contribute to regression of liver fibrosis in mice. Hepatology 2007;45:213-222.

98 Ferguson MW, Duncan J, Bond J, et al: Prophylactic administration of avotermin for improvement of skin scarring: three doubleblind, placebo-controlled, phase I/II studies. Lancet 2009;373:1264-1274. 
99 Kuhn A, Haust M, Ruland V, et al: Effect of bosentan on skin fibrosis in patients with systemic sclerosis: a prospective, open-label, non-comparative trial. Rheumatology (Oxford) 2010;49:1336-1345.

100 el-Agroudy AE, Hassan NA, Foda MA, et al: Effect of angiotensin II receptor blocker on plasma levels of TGF- $\beta 1$ and interstitial fibrosis in hypertensive kidney transplant patients. Am J Nephrol 2003;23:300-306.

101 King TE Jr, Brown KK, Raghu G, et al: BUILD-3: a randomized, controlled trial of bosentan in idiopathic pulmonary fibrosis. Am J Respir Crit Care Med 2011;184:9299.

102 Noble PW, Albera C, Bradford WZ, et al: Pirfenidone in patients with idiopathic pulmonary fibrosis (CAPACITY): two randomised trials. Lancet 2011;377:17601769.
103 Diez J, Querejeta R, Lopez B, et al: Losartandependent regression of myocardial fibrosis is associated with reduction of left ventricular chamber stiffness in hypertensive patients. Circulation 2002;105:2512-2517.

104 Yamamoto T, Fazio VW, Tekkis PP: Safety and efficacy of strictureplasty for Crohn's disease: a systematic review and meta-analysis. Dis Colon Rectum 2007;50:19681986.

105 Fazio VW, Tjandra JJ, Lavery IC, et al: Long-term follow-up of strictureplasty in Crohn's disease. Dis Colon Rectum 1993; 36:355-361.

106 Maconi G, Sampietro GM, Cristaldi M, et al: Preoperative characteristics and postoperative behavior of bowel wall on risk of recurrence after conservative surgery in Crohn's disease: a prospective study. Ann Surg 2001;233:345-352.
07 Wynn TA, Ramalingam TR: Mechanisms of fibrosis: therapeutic translation for fibrotic disease. Nat Med 2012;18:10281040.

08 Iimuro Y, Nishio T, Morimoto T, et al: Delivery of matrix metalloproteinase- 1 attenuates established liver fibrosis in the rat. Gastroenterology 2003;124:445-458.

109 Kokot A, Sindrilaru A, Schiller M, et al: a-Melanocyte-stimulating hormone suppresses bleomycin-induced collagen synthesis and reduces tissue fibrosis in a mouse model of scleroderma: melanocortin peptides as a novel treatment strategy for scleroderma? Arthritis Rheum 2009;60: 592-603. 